\title{
Sleep Apnea in Patients with Acromegaly. Frequency, Characterization and Positive Pressure Titration
}

\author{
Daniel Hernández-Gordillo ${ }^{1}$, María del Rocío Ortega-Gómez², \\ Lourdes Galicia-Polo ${ }^{1}$, Armando Castorena-Maldonado ${ }^{1}$, \\ Alma Vergara-López², Miguel Ángel Guillén-González ${ }^{2}$ \\ and Luis Torre-Bouscoulet ${ }^{*}, 1,3$
}

\author{
${ }^{I}$ Sleep Medicine Unit, National Institute of Respiratory Diseases; Mexico City, Mexico \\ ${ }^{2}$ Department of Endocrinology, Centro Médico Nacional "20 de Noviembre”; Mexico City, Mexico \\ ${ }^{3}$ Department of Respiratory Physiology, National Institute of Respiratory Diseases; Mexico City, Mexico
}

\begin{abstract}
Objectives: (1) to describe the frequency of sleep apnea in patients with acromegaly; (2) to identify the proportion of candidates for treatment with positive airway pressure; and, (3) to report our experience with the positive pressure titration process in acromegaly patients.

Methods: A cross-sectional study that included the acromegaly cohort at the Centro Medico Nacional "20 de Noviembre" in Mexico City ( $\mathrm{n}=44)$. A standard polysomnography (PSG) was carried out for each patient. A second PSG was done for purposes of CPAP titration.

Results: A total of 35 patients were studied (80\% of the cohort, 20 [57\%] women). Polysomnography results showed that 34 subjects $(97 \%, 95 \% \mathrm{CI} 91-100 \%)$ had apnea hypopnea indexes (AHI) $\geq 5$. No patient had central apnea. We identified 19 subjects with $\mathrm{AHI} \geq 5$ and Epworth $\geq 10$, for a frequency of obstructive sleep apnea syndrome of $54 \%$ (95\%CI 36-71\%). A total of 31 patients $(88 \%$; $95 \%$ CI $77-99 \%)$ were deemed to be candidates for positive pressure treatment, but only 8 of them accepted CPAP. They required pressures that ranged from 10 to $18 \mathrm{cmH}_{2} \mathrm{O}$.

Conclusions: Our results confirm a high prevalence of sleep apnea in patients with acromegaly, and provide evidence that the majority of those patients are candidates for treatment with positive pressure. Contrary to what has been reported, we identified no patients with central apnea.
\end{abstract}

Keywords: Acromegaly, sleep, sleep apnea, sleep-disordered breathing, growth hormone.

\section{INTRODUCTION}

Acromegaly is a disease characterized by an excessive secretion of growth hormone $(\mathrm{GH})$ and insulin-like growth factor type 1 (IGF-1) [1]. Though the incidence of this illness is low (3-4 cases per million inhabitants per year) and there is a wide range of treatment modalities available, life expectancy is reduced by at least 10 years due, primarily, to mortality caused by cardiovascular factors [2].

Though information exists on the high frequency of SDB in patients with acromegaly, those disorders have been poorly characterized and little is known about the daytime symptoms of patients with acromegaly who experience SDB. Finally, there is no data on positive pressure titration as a therapeutic measure applied in acromegaly patients [3-6].

Therefore, the objectives of this study were, first, to describe the frequency of sleep apnea in a cohort of patients with acromegaly; second, to identify the proportion of

*Address correspondence to this author at the Departamento de Fisiología Respiratoria y Clínica de Trastornos Respiratorios del Dormir, Instituto Nacional de Enfermedades Respiratorias, Tlalpan 4502, Colonia Sección XVI, Delegación Tlalpan CP 14080, D.F. México; Tel/Fax: (52) (55) 56654748; E-mail: luistorreb@gmail.com patients with acromegaly and sleep apnea that are candidates for treatment with positive pressure; and, third, to report our experience with the titration process of positive pressure in patients with this disease.

\section{METHODS}

This study was approved by the Science and Bioethics Committee of the Instituto Nacional de Enfermedades Respiratorias (code C04-09). Participants in the study signed an informed consent form. Data confidentiality was maintained at all times.

This is a cross-sectional study in which all patients of the acromegaly cohort at the Centro Medico Nacional "20 de Noviembre" in Mexico City were invited to participate. At the time the study was undertaken that cohort included 44 patients. The diagnosis of acromegaly was made according to the accepted international criteria [7-9].

Once patients had agreed to participate in the study, they filled in questionnaires on their habits and symptoms related to sleep, including a validated Spanish version of the Epworth Sleepiness Scale (ESS) [10]. Anthropometric measurements were made using an electronic scale (Tanita ${ }^{\mathrm{TM}}$, Japan, precision $\pm 200 \mathrm{~g}$ ), and a stadimeter (SECA 
$240^{\mathrm{TM}}$, Hamburg, Germany, precision $\pm 0.2 \mathrm{~cm}$ ). Body mass index (BMI) was obtained through the following formula: BMI $=\left(\right.$ weight $\left./ h \operatorname{sh}^{2}\right)$. Neck circumference was measured at the level of the cricoid cartilage using a non-extendible, polycarbonate tape measure. Blood pressure was measured using a mercury manometer after patients had remained at rest for 5 minutes. All measurements were made by a single researcher (DHG).

The polysomnography studies were conducted using a 16-channel Grass Instrument (model 15LT-PSGA, Gamma 4.1 version, West Warwick, Rhode Island, USA), or a 32channel Alice Sleepware device (version 5, model 1018958, Respironics brand, Murrysville, Pennsylvania, USA). All studies were conducted in accordance with the American Academy of Sleep Medicine's recommendations (AASM, 2007) [11]. The montage utilized included electroencephalography derivations: frontal, central and right occipital (F4-M1, C4-M1, O2-M1), left and right electrooculograms (EOG), electromyograms (EMG) of the chin, EMGs of the tibialis anterior muscle to detect leg movements, and electrocardiogram channel obtained through a unipolar derivation. Airflow was measured simultaneously using an oronasal thermistor and a pressure transducer (Respironics Sleep Sense ${ }^{\mathrm{TM}}$ brand, Murrysville, Pennsylvania, USA), while respiratory movements of the thorax and abdomen were determined through inductance plethysmography (Respiband ${ }^{\mathrm{TM}}$; New York, USA, or bands, Pro tech ${ }^{\mathrm{TM}}$, Murrysville, Pennsylvania, USA). The state of oxygenation was measured by pulse oximetry (Massimo $^{\mathrm{TM}}$ set Irvine, USA). The studies were assessed in 30-second epochs in order to identify sleep stages in accordance with the guidelines established by the AASM (2007) [11]. Apnea was considered to be obstructive when a decline in the thermal sensor's peak $\geq 90 \%$ from baseline for at least 10 seconds was observed, together with the presence of continuous or augmented respiratory movement throughout the event. Central apnea, meanwhile, was defined as a decline in the peak of the thermal sensor $\geq 90 \%$ from baseline for at least 10 seconds with an absence of respiratory movement during the entire event. Mixed apnea was diagnosed by a decline in the peak of the thermal sensor $\geq 90 \%$ from baseline for at least 10 seconds associated with an absence of inspiratory effort at the initial part of the event, followed by the resumption of that effort during the second part of the event. Hypopnea was identified on the basis of a reduction $\geq 30 \%$ in the signal from the pressure cannula with respect to baseline for a duration of at least 10 seconds, associated with desaturation $\geq 4 \%$ and when at least $90 \%$ of the time of the event satisfied the reduction criteria for the pressure signal.

Patients with severe apnea (apnea hypopnea index, AHI $>30$ ), as well as those with AHI between 5 and 30 with Epworth $\geq 10$ points, and patients with AHI between 5 and 30 with Epworth below 10 points and high cardiovascular risk were judged to be candidates for CPAP treatment [12].

\section{Statistical Analysis}

Most of the variables showed asymmetrical distributions; therefore, data are presented as medians, interquartile intervals (IQI) and minimum and maximum values. The categorical variables were described as frequencies and percentages using $95 \%$ confidence intervals $(95 \% \mathrm{CI})$. Associations were explored using Spearman's coefficient correlation, while group comparisons were carried out -as appropriate- using the Wilcoxon Rank-Sum Test or the $X^{2}$. Data analysis was conducted using a commercially available statistical package (Stata, release 9.2, StataCorp, College Station, TX, USA).

\section{RESULTS}

The original cohort consisted of 44 patients, but 9 declined to participate. Thus, 35 patients were studied (response rate $80 \%$ ). No differences were found in age, gender, ESS or IGF-1 between responders $(\mathrm{n}=35)$ vs nonresponders $(\mathrm{n}=9)$. Of these individuals, 20 were women $(57 \%)$ and 15 were men (43\%). Table 1 shows their general characteristics.

Table 1. General Characteristics of the Patients

\begin{tabular}{|c|c|}
\hline Parameter & Value \\
\hline Age (years)* & $51(39-63) 13-85$ \\
\hline Age at diagnosis (years)* & $47(35-52)(13-71)$ \\
\hline Weight (Kg) & $75(68-88) 49-137$ \\
\hline Height (m)* & $1.62(1.56-1.70) 1.43-1.82$ \\
\hline $\mathrm{BMI}\left(\mathrm{Kg} \cdot \mathrm{m}^{-2}\right)^{*}$ & $29(26-33) 22-46$ \\
\hline $\mathrm{NC}(\mathrm{cm})^{*}$ & $38(35-40) 32-50$ \\
\hline Years since diagnosis of acromegaly* & $4(3-10) 0-30$ \\
\hline Patients subjected to surgery ${ }^{\mathrm{a}} \mathrm{n}(\%)$ & $28(80)$ \\
\hline Patients subjected to radiation therapy $\mathrm{n}(\%)$ & $14(40)$ \\
\hline Months receiving octreotide* & $30(20-36) 3-62$ \\
\hline Controlled patients n (\%) & $28(80)$ \\
\hline Uncontrolled patients n (\%) & $7(20)$ \\
\hline \multicolumn{2}{|c|}{ Sleep-Related Symptoms } \\
\hline Patients with snoring $\mathrm{n}(\%)$ & $31(91)$ \\
\hline Patients with insomnia n (\%) & $26(76)$ \\
\hline Patients with observed apneas n (\%) & $10(30)$ \\
\hline Hypertension $^{\mathrm{b}} \mathrm{n}(\%)$ & $20(59)$ \\
\hline Mallampati score* & $2(2-3) 1-4$ \\
\hline Tonsillar grade ${ }^{c} *$ & $1(1-2) 0-3$ \\
\hline Daytime $\mathrm{SpO}_{2} \% *$ & $93(92-95) 86-96$ \\
\hline Epworth Scale score* & $10(6-15) 2-24$ \\
\hline Epworth $\geq 10 \mathrm{n}(\%)$ & $20(59)$ \\
\hline
\end{tabular}

BMI: body mass index, $\mathrm{NC}$ : neck circumference, $\mathrm{SpO}_{2} \%$ : oxygen saturation by pulse oxymetry.

* Mean (interquartile Interval) min. - max.

${ }^{\text {a }}$ Surgery to resect the pituitary adenoma.

${ }^{\mathrm{b}}$ Medical diagnosis of hypertension; or on antihypertensive treatment; or blood pressure greater than $140 / 90 \mathrm{mmHg}$.

"Grade 0: tonsillectomy; grade 1: tonsils were in the tonsillar fossa; grade 2: tonsils were visible behind the anterior pillars; grade 3 : tonsils extended three-quarters of the way to the midline; grade 4: tonsils were completely obstructing the airway [25].

Table 2 shows the results of the polysomnography studies. In order for a test to be considered adequate for 
interpretation, sleep efficiency had to reach at least the level of $80 \%$. One patient was studied on two occasions because on the first sleep efficiency was below $80 \%$. Sleep efficiency for the group as a whole showed a mean of $87 \%$ (IQI 82-92). In the majority of patients $(97 \%$; 95\%CI 91-100), tests revealed an AHI considered "abnormal" ( $\geq 5$ events/hour), and in $60 \%$ of patients, AHI was above the cutoff point for "severity" ( $\geq 30$ events/hour). Nineteen patients $(54 \%$, $95 \%$ CI $36-71 \%$ ) satisfied the usual criteria of obstructive sleep apnea syndrome (AHI $\geq 5$ events/hour with and Epworth score $\geq 10$ ). Alterations of sleep architecture were documented: the mean for slow-wave sleep was $16 \%$ (IQI 10-21), while that of REM sleep (R sleep) was $15 \%$ (IQI 1318), with an average of 30 alerts per hour of sleep. Upon comparing men and women, no significant differences were found in the frequency of apnea, the severity of the disease, the need for treatment, the Epworth Sleepiness Scale, or any of the other variables evaluated (Table 3).

Table 2. Results of Polysomnography Studies

\begin{tabular}{|c|c|}
\hline Parameter & Value \\
\hline Sleep efficiency $(\%)^{*}$ & $87(82-92) 56-98$ \\
\hline Latency to $1^{\text {st }}$ stage of sleep (minutes)* & $16(12-21) 0-59$ \\
\hline Latency to REM (minutes)* & $89(74-128) 50-339$ \\
\hline N1 $(\%)^{*}$ & $14(12-19) 3.2-52$ \\
\hline N2 $(\%)^{*}$ & $51(46-58) 37-71$ \\
\hline N3 $(\%)^{*}$ & $16(10-21) 0.6-31$ \\
\hline NREM $(\%)^{*}$ & $85(82-88) 72-92$ \\
\hline $\operatorname{REM}(\%) *$ & $15(13-18) 9-27$ \\
\hline Index of arousals* & $30(23-42) 8-82$ \\
\hline Index of respiratory arousals* & $16(5-26) 0-66$ \\
\hline Central apneas* & $1(0-5) 0-97$ \\
\hline Mixed apneas* & $0.2(0-2.4) 0-60$ \\
\hline Obstructive apneas* & $54(9-146) 1-637$ \\
\hline Hypopneas* & $169(82-219) 0-327$ \\
\hline Central apnea index (events/hr)* & $0.1(0-0.7) 0.1-14.2$ \\
\hline Obstructive apnea index (events/hr)* & $9(1.3-20) 0.1-84$ \\
\hline AHI (events/hr)* & $34(22-57) 3.3-108$ \\
\hline $\mathrm{AHI}<5$ n $(\%)$ & $1(3)$ \\
\hline $\mathrm{AHI} \geq 5$ and $<15, \mathrm{n}(\%)$ & $7(20)$ \\
\hline $\mathrm{AHI} \geq 15$ and $<30, \mathrm{n}(\%)$ & $6(17)$ \\
\hline $\mathrm{AHI} \geq 30, \mathrm{n}(\%)$ & $21(60)$ \\
\hline $\mathrm{SpO}_{2}$ while laying awake* & $93(90-94) 82-96$ \\
\hline Average $\mathrm{SpO}_{2}$ during sleep* & $90(87-92) 62-95$ \\
\hline $\mathrm{REM} \mathrm{SpO}_{2} *$ & $89(86-92) 56-95$ \\
\hline $\mathrm{NREM} \mathrm{SpO}_{2} *$ & $90(87-92) 67-95$ \\
\hline $\mathrm{AHI} \geq 5$ and Epworth $\geq 10, \mathrm{n}(\%)$ & $19(54)$ \\
\hline
\end{tabular}

REM: rapid eye-movement sleep, NREM: non-rapid eye-movement sleep, AHI: apneahypopnea index, $\mathrm{SpO}_{2}$ : percentage of saturation by pulse oxymetry.

*Mean (interquartile interval) min. - max.
Seven patients had "uncontrolled" acromegaly, though IGF-1 levels were not found to be associated with either the AHI or central apneas. The correlation between the IGF-1 levels and the index of central apneas was not significant $(\mathrm{p}$ $=0.98)$, nor did we find any difference between the controlled $(\mathrm{n}=28)$ versus the uncontrolled patients $(\mathrm{n}=7)$ with respect to sleep architecture or respiratory indexes.

All patients received octreotide for at least 3 months from the onset of treatment. The study did not demonstrate any associations between the duration of treatment and the severity of the apnea $\left(r_{s}=0.13\right)$, or between the degree of sleepiness and the activity of the acromegaly $\left(r_{\mathrm{s}}=0.15\right)$ or the number of years since diagnosis $\left(r_{s}=-0.11\right)$, or between AHI and the Epworth Scale $\left(r_{s}=0.03\right)$. A weak association between AHI and body mass index was found $\left(r_{s}=0.35, p=\right.$ $0.03)$, but no association with neck circumference $\left(r_{\mathrm{s}}=0.16\right.$, $\mathrm{p}=0.37$ ) was documented. We also compared patients according to excessive daytime sleepiness (ESS $\geq 10$ vs ESS $<10$ ) but found no significant differences in age, BMI, IGF1 , months of treatment with octreotide, or years since diagnosis.

Of the 35 patients studied, 31 were considered candidates for CPAP treatment (88\%, 95\%CI 77-99\%). Those patients were classified as follows: (a) 9 (26\%) with AHI $\geq 30$ events/hour; (b) 19 (54\%) with AHI between 5 and 30 events/hour and Epworth $\geq 10$; and, (c) 3 (8\%) with AHI between 5 and 30 events/hour with Epworth $<10$ and systemic arterial hypertension.

The 31 patients judged to be candidates for treatment with positive pressure were invited to undergo a second polysomnograph for pressure titration, but only 8 of them (26\%) agreed to undergo the test. These results are shown in Table 4. Three of these patients were titrated using both the CPAP and bi-level methods (patients 1,2 and 6), but the latter showed no advantages over CPAP in terms of sleep architecture, residual AHI, tolerance, or gas exchange. One patient did not tolerate CPAP. Optimal CPAP pressures ranged from 12 to $18 \mathrm{cmH}_{2} \mathrm{O}$.

\section{DISCUSSION}

The principal results of this study are as follows: (1) almost all patients (97\%) presented abnormal AHI; (2) just over half of the patients (54\%) had AHI $\geq 5$ and Epworth $\geq 10$; (3) $88 \%$ of patients were candidates for CPAP treatment; (4) contrary to reports by other authors, we did not identify patients with central apnea in our cohort; and, (5) CPAP treatment seems to be efficient in most patients with acromegaly; while the bi-level method does not appear to have advantages over CPAP.

The prevalence reported for sleep apnea in patients with acromegaly varies from 19 to $81 \%$, depending on the methods and diagnosis criteria used [13]. Given that these figures differ from the prevalence of sleep apnea in the general population $-2 \%$ and $4 \%$ for women and men, respectively-[14,15] it is suggested that acromegaly is a risk factor for the development of sleep apnea. In this study, the diagnostic method utilized was nocturnal polysomnography, which allowed researchers to identify (according to current staging standards), that $97 \%$ of patients with acromegaly have abnormal AHI, and that the prevalence of obstructive sleep apnea syndrome -defined as AHI $\geq 5$ events/hour and 
Table 3. Comparison of Polysomnographic Findings Between Men and Women

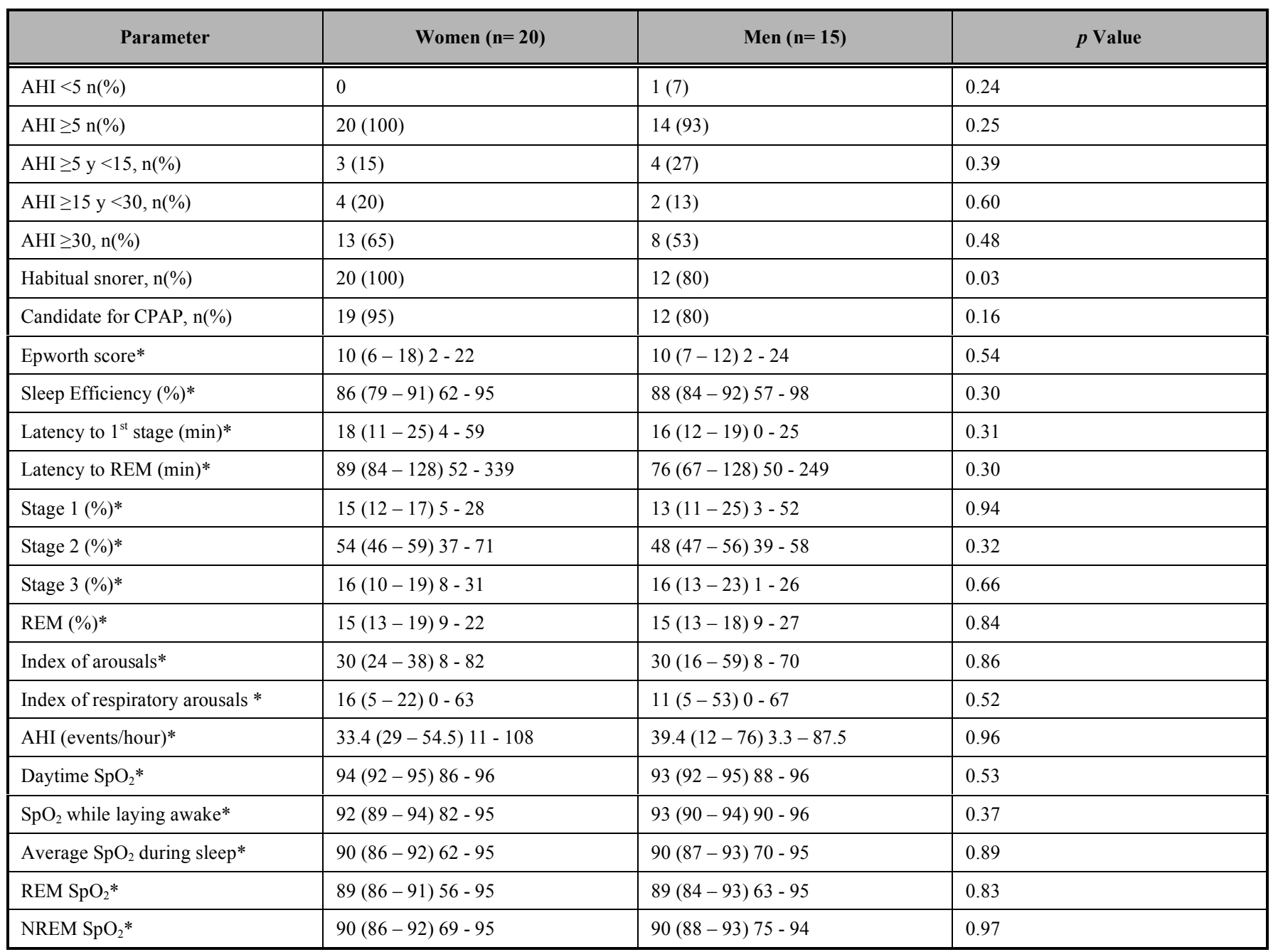

AHI: apnea-hypopnea index, CPAP: continuous positive airway pressure, REM: rapid eye-movement sleep, NREM: non-rapid eye-movement sleep, $\mathrm{SpO}_{2}$ : percentage of saturation by pulse oxymetry.

* Mean (Interquartile interval) min. - max.

Table 4. Patients Titrated with CPAP

\begin{tabular}{|c|c|c|c|c|c|c|c|c|c|c|}
\hline Patient & Gender & Age & BMI & $\begin{array}{l}\text { Epworth } \\
\text { Scale Score }\end{array}$ & $\begin{array}{c}\text { Average } \mathrm{SpO}_{2} \\
\text { During Sleep }\end{array}$ & AHI & $\begin{array}{l}\text { CPAP Pressure } \\
\left(\mathrm{cmH}_{2} \mathbf{0}\right)\end{array}$ & $\begin{array}{c}\text { Residual AHI } \\
\text { with CPAP }\end{array}$ & $\begin{array}{c}\text { Average } \mathrm{SpO}_{2} \\
\text { with CPAP }\end{array}$ & $\begin{array}{c}\text { Supplementary } \\
\text { Oxygen }\end{array}$ \\
\hline 1 & $\mathrm{~F}$ & 53 & 30 & 6 & 69 & 108 & 16 & 0 & 84 & Yes \\
\hline 2 & M & 38 & 46 & 15 & 70 & 70 & 18 & & 94 & No \\
\hline 3 & M & 64 & 27 & 12 & 87 & 70 & Did not tolerate & - & 87 & Yes \\
\hline 4 & $\mathrm{~F}$ & 34 & 25 & 15 & 91 & 28 & 14 & 3 & 91 & No \\
\hline 6 & M & 68 & 27 & 11 & 90 & 27 & 12 & 9 & 92 & No \\
\hline 7 & $\mathrm{~F}$ & 43 & 30 & 16 & 92 & 51 & 11 & & 93 & No \\
\hline 8 & F & 50 & 42 & 10 & 86 & 54 & 12 & 0 & 91 & No \\
\hline
\end{tabular}

F: Female. M: Male. BMI: body mass index in $\mathrm{Kg} \cdot \mathrm{m}^{-2}$. $\mathrm{SpO}_{2}$ : percentage of saturation by pulse oxymetry. AHI: total apnea hypopnea index.

Epworth $\geq 10$ - was $54 \%$. To the best of our knowledge, this is the first report on the frequency of sleep apnea in patients with acromegaly to utilize the current scoring rules and recommendations, published by the American Academy of Sleep Medicine in 2007 [11].
Though we cannot affirm that an $\mathrm{AHI} \geq 5$ in patients with acromegaly is equally deleterious as in patients who do not suffer from this disease, intuitively we could consider that the high cardiovascular risk seen in patients with acromegaly might be due, at least in part, to their high frequency of sleep 
apnea. Sleep apnea is considered an independent risk factor of cardiovascular morbidity; nonetheless, the mechanisms underlying this association are not well known [16-19]. There is evidence to suggest that the hypoxemiareoxygenation phenomenon induces an "oxidative" state that has harmful consequences for endothelial functioning and the atherogenic process, in addition to inducing a systemic inflammatory condition. Other mechanisms that cause cardiovascular damage include high sympathetic activation, changes in intrathoracic pressure and the hypo-hypercapnia phenomenon [19]. The participation of these mechanisms in the development of cardiovascular diseases in patients with acromegaly remains to be clarified.

Another significant finding documented by this study is that $54 \%$ of patients suffer from obstructive sleep apnea syndrome (AHI $\geq 5$ and Epworth $\geq 10$ ). Clearly, all those patients are candidates for treatment. Upon adding other groups who meet the criteria for receiving treatment, it was possible to determine that $88 \%$ are candidates for CPAP, but additional studies are needed to evaluate the effect of CPAP on cardiovascular morbidity and mortality in patients with acromegaly. Another additional salient point to explore is whether the craniofacial abnormalities of such patients negatively affect long-term adherence to CPAP.

Other factors not associated with the craniofacial abnormalities may potentially explain the high frequency of sleep apnea observed in patients with acromegaly. For example, chronic exposure to high altitudes in untreated patients with obstructive sleep apnea aggravates hypoxemia and increases sleep-related breathing disturbances due to frequent central apneas/hypopneas [20]. This factor could lead to an overestimate of the prevalence of sleep apnea in our cohort, given that Mexico City is at 2240 meters above sea level. However, as shown in Table 2, the AHI observed in our patients were due mainly to obstructive, not central, disturbances; moreover, they were acclimatized residents of Mexico City and previous data from our group $(n=23)$ demonstrated that, in healthy people living at that altitude, the median of AHI was 3.3 events/hr and sleep architecture was similar to that described in other studies carried out at sea level [21]. Therefore, we do not believe that altitude is a significant element in the high frequency of sleep apnea observed in patients with acromegaly. Another potential confounder is obesity; however, only a weak association between AHI and body mass index was found, and no association with neck circumference was recognized; suggesting that the high frequency of sleep apnea observed in our patients could be predominantly a consequence of their craniofacial abnormalities, and not of obesity as is seen in the general population [22].

Previous studies have established an association between the number of central apneas and the activity of this disease (IGF-1 levels). However, we did not encounter this association in our patients, and in no case was the presence of central apneas above $50 \%$ of total AHI. Treatment with octreotide may explain this finding, as all patients had been taking that medication for at least 3 months, and earlier research has shown that this therapy reduces the severity of the illness, at the cost of diminishing the number of central apneas [23].
Finally, our study has limitations. First, all our patients were being treated with octreotide, which impedes us from speculating on the frequency of sleep apnea in patients who are virgins in terms of treatment. Second, we were unable to include control subjects matched for age and BMI, a fact that impedes any affirmation as to whether those potential confounders may be contributing to the high frequency of sleep apnea in patients with acromegaly. Third, the response rate to CPAP titration was low $(25 \%)$, a fact that limits the external validity of the data obtained from the titration process using positive pressure; however, though we were unable to determine why so few patients accepted CPAP, we believe that factors other than medical reasons are involved; for instance, economic conditions had some effect because patients' had to purchase the CPAP device (it could not be provided by the study, nor is it covered by Mexico's national health system). Also, several patients were unwilling to undergo CPAP titration because they had many medical appointments in different hospitals. Nonetheless, our study did have the second-largest series in terms of the number of patients studied using the reference standards and following the current guidelines for staging. Moreover, it is the first report to explore the CPAP titration process in patients with acromegaly.

In conclusion, there is a high frequency of sleep apnea in patients with acromegaly (97\%), the majority of whom $(90 \%)$ are candidates for CPAP treatment. In contrast to what is consistently observed in the general population, we did not identify any difference in the frequency of sleep apnea between men and women; nor did we observe patients with acromegaly under treatment with octreotide who had central sleep apnea. Our results thus provide evidence that, regardless of disease activity, acromegaly patients must be examined routinely to detect sleep apnea. Additional studies are required to explore whether CPAP treatment reduces the cardiovascular morbidity and mortality seen in patients with acromegaly.

\section{ACKNOWLEDGEMENTS}

The authors wish to express their gratitude to the patients who kindly agreed to participate in this research, and to Dr. José Luis Carrillo Alduenda for his invaluable support during the realization of the study itself. The authors would also like to thank Mr. Paul Kersey (Language Laboratory, El Colegio de Michoacán) for correcting language use.

\section{CONFLICT OF INTEREST}

Declared none.

\section{REFERENCES}

[1] Ben-Sholmo A, Melmed S. Acromegaly. Endocrinol Metab Clin North Am 2008; 37: 101-22.

[2] Mestron A, Webb SM, Astorga R, et al. Epidemiology, clinical characteristics, outcome, morbidity and mortality in acromegaly based on the Spanish Acromegaly Registry (Registro Espanol de Acromegalia, REA). Eur J Endocrinol 2004; 151: 439-46.

[3] Hochban W, Ehlenz K, Conradt R, Brandenburg U. Obstructive sleep apnoea in acromegaly: the role of craniofacial changes. Eur Respir J 1999; 14: 196-202.

[4] Isono S, Saeki N, Tanaka A, Nishino T. Collapsibility of passive pharynx in patients with acromegaly. Am J Respir Crit Care Med 1999; 160: 64-8.

[5] Grunstein RR, Ho KY, Sullivan CE. Sleep apnea in acromegaly. Ann Intern Med 1991; 115: 527-32. 
[6] Rosenow F, Reuter S, Deuss U, et al. Sleep apnoea in treated acromegaly: relative frequency and predisposing factors. Clin Endocrinol (Oxf) 1996; 45: 563-9.

[7] Cook DM, Ezzat S, Katznelson L, et al. AACE Acromegaly Guidelines Task Force. AACE Medical Guidelines for Clinical Practice for the diagnosis and treatment of acromegaly. Endocr Pract 2004; 10: 213-25.

[8] Melmed S, Colao A, Barkan A, et al. Guidelines for acromegaly management: an update. J Clin Endocrinol Metab 2009; 94: 150917.

[9] Giustina A, Barkan A, Casanueva FF, et al. Criteria for cure of acromegaly: a consensus statement. J Clin Endocrinol Metab 2000; 85: 526-9.

[10] Chiner E, Arriero JM, Signes-Costa J, Marco J, Fuentes I. Validation of the Spanish version of the Epworth Sleepiness Scale in patients with a sleep apnea syndrome. Arch Bronconeumol 1999; 35: 422-7.

[11] Iber C, Ancoli-Israel S, Chesson AL, Quan SF. The AASM Manual for the Scoring of Sleep and associated events. Rules, terminology and technical specifications. Westchester IL: American Academy of Sleep Medicine 2007.

[12] Loube DI, Gay PC, Strohl KP, Pack AI, White DP, Collop NA. Indications for positive airway pressure treatment of adult obstructive sleep apnea patients: a consensus statement. Chest 1999; 115: 863-6.

[13] Fatti LM, Scacchi M, Pincelli AI, Lavezzi E, Cavagnini F. Prevalence and pathogenesis of sleep apnea and lung disease in acromegaly. Pituitary 2001; 4: 259-62.

[14] Young T, Palta M, Dempsey J, Skatrud J, Weber S, Badr S. The occurrence of sleep-disordered breathing among middle-aged adults. N Engl J Med 1993; 328: 1230-5.
[15] Bouscoulet LT, Vazquez-Garcia JC, Muino A, et al. Prevalence of sleep related symptoms in four Latin American cities. J Clin Sleep Med 2008; 4: 579-85.

[16] Peppard PE, Young T, Palta M, Skatrud J. Prospective study of the association between sleep-disordered breathing and hypertension. N Engl J Med 2000; 342: 1378-84.

[17] Gami AS, Howard DE, Olson EJ, Somers VK. Day-night pattern of sudden death in obstructive sleep apnea. N Engl J Med 2005; 352: 1206-14.

[18] Yaggi HK, Concato J, Kernan WN, Lichtman JH, Brass LM, Mohsenin V. Obstructive sleep apnea as a risk factor for stroke and death. N Engl J Med 2005; 353: 2034-41.

[19] Torre-Bouscoulet L, Castorena-Maldonado A, Sada-Ovalle I, Meza-Vargas MS. Mechanisms of cardiovascular damage in obstructive sleep apnea. Rev Invest Clin 2008; 60: 502-16.

[20] Nussbaumer-Ochsner Y, Schuepfer N, Ulrich S, Bloch KE. Exacerbation of sleep apnoea by frequent central events in patients with the obstructive sleep apnea syndrome at altitude: a randomized trial. Thorax 2010; 65: 429-35.

[21] Hernández-Zenteno RJ, Pérez-Padilla R, Vázquez JC. Normal breathing during sleep at an altitude of 2,240 meters. Arch Med Res 2002; 33: 489-94

[22] Young T, Shahar E, Nieto FJ, et al. Predictors of sleep-disordered breathing in community-dwelling adults: the sleep heart health study. Arch Intern Med 2002; 162: 893-900.

[23] Grunstein RR, Ho KK, Sullivan CE. Effect of octreotide, a somatostatin analog, on sleep apnea in patients with acromegaly. Ann Intern Med 1994; 121: 478-83.

(C) Hernández-Gordillo et al.; Licensee Bentham Open.

This is an open access article licensed under the terms of the Creative Commons Attribution Non-Commercial License (http://creativecommons.org/licenses/by-nc/3.0/) which permits unrestricted, non-commercial use, distribution and reproduction in any medium, provided the work is properly cited. 